\title{
Hydrological Response to Land Use and Land Cover Changes of Ribb Watershed, Ethiopia
}

\author{
Solomon Bogale \\ Department of Hydraulic and Water Resources Engineering, Debre Markos University, Debre Markos, Ethiopia \\ Email address: \\ Solomonbogale89@gmail.com \\ To cite this article: \\ Solomon Bogale. Hydrological Response to Land Use and Land Cover Changes of Ribb Watershed, Ethiopia. Hydrology. \\ Vol. 9, No. 1, 2021, pp. 1-12. doi: 10.11648/j.hyd.20210901.11
}

Received: December 11, 2020; Accepted: December 21, 2020; Published: March 12, 2021

\begin{abstract}
The study analyzed the present land covers that have taken place in the catchment and its effect on the hydrological responses of the catchment. The Soil and Water Assessment Tool (SWAT2009) model was used to investigate the impact of land cover change on hydrological responses of the study area. Sensitivity analysis result shown SCN curve number $(\mathrm{CN})$, Soil Evaporation Compensation Factor (ESCO), Soil Depth (m) (Sol_Z), Threshold water depth in the shallow aquifer for flow (GWQMN), Base flow alpha factor (Alpha_Bf), (REVAPMN) and Soil Available Water Capacity (SOL_AWC) were found the most influential parameters affecting flow and USLE equation support practice (USLE_P), Linear parameter for maximum sediment yield (SPCON), Exponential parameter for maximum sediment yield in channel sediment routing (SPEXP), Cropping practice factor (USLE_C), channel cover factor $(\mathrm{CH}$ COV1), channel erodiability factor (CH_ERODMO) were the most sensitive parameters affecting sediment yield of the catchment respectively. Scenarios were developed to analyze the impact of land use/cover changes to the hydrological regime. Base scenario: current land use practices has cultivated land, grass land, shrub and bush land, forest land, built up area and water body, scenario1: shrub and bush lands completely changed to forest land and scenario2: Grass land changed to cultivated land. The result for different land use scenarios show that: conversion of shrub land to forest area reduced surface runoff, reduced the amount of sediment transported out and increase base flow but conversion of grass land in to cultivated land areas increased surface runoff during wet seasons and reduced base flow during the dry seasons and also as the peak flow increases it is suspected of carrying more sediment.
\end{abstract}

Keywords: SWAT, LULCC, SUFI-2, Ribb, Stream Flow, Sediment Yield, Hydrological Modeling, Water Balance, Model Calibration, Validation

\section{Introduction}

As a result of the loss of natural vegetation and the fragmentation or separation of natural areas, land use land cover change (LULCC) may be a major threat to biodiversity [1]. It is one of the major hydrological system altering behaviors caused by humans. One of the challenges in recent hydrological research is to consider the impacts of different environmental changes and measure the influence of LULCC on the hydrological dynamics of a catchment [2].

Significant changes have taken place in the LULCC, especially in developing countries with agricultural-based economies and rapidly growing populations. A number of natural and human driving forces are responsible for triggering LULCC. Natural causes, such as climate change, are only long-term, whereas human activities can change hydrological and watershed processes drastically [3].

The amount of evaporation, groundwater infiltration and overland flow occurring during and after precipitation events are directly influenced by LULCC [4]. In the short term, destructive changes in land use will influence the hydrological cycle either by raising the yield of water or by reducing or even removing low flow in some circumferences. In recent years, the areas suffering from extreme floods have caused damage to homes, different infrastructures and caused the loss of human life, affecting socio-economic activities. There is therefore a clear need for hydrological techniques and resources to determine the possible impact of changes in land cover on the hydrological response of a catchment [5]. These strategies and tools will provide knowledge that can be used at the watershed level for water resource management and encourage local government officials to prepare the 
potential problem solving initiative for appropriate action through future growth progress [6]. It is important to understand the effect of the LULC transition on the hydrology of the Ribb River watershed with the above and other related problems [7]. Therefore it is necessary to understand how LULCC affects the hydrological condition of the watershed for planners to develop policies to mitigate the adverse effects of future land cover changes for sustainable resource management [2]. The quantification of LULC changes within a catchment is an important component of watershed quality monitoring, among other things. It is also important to understand watershed hydrology, particularly the physical processes that occur and the control factors within the watersheds [8]. The study of hydrological processes responding to land cover changes offers useful insights into how the flow of the river will respond to these changes. It is understood that river flow is an integrated measure of the processes of the entire watershed. In addition to the prediction of watershed hydrology on various land use/cover dynamics, options for planning and control of water supplies for future watershed management are used to prioritize [9].
In general, this research is to examine the effects of land use land cover change on Ribb River watershed hydrology, upper Blue Nile, to establish Ribb catchment land use/land cover map, to calibrate and validate stream flow and sediment yield and to evaluate the hydrological (SWAT) model output and to evaluate the catchment's stream flow and sediment yield response to the change in catchment flow and sediment yield.

\section{Materials and Methods}

\section{Description of study area}

The Ribb River watershed study area is located east of Lake Tana, South Gondar Zonein Amhara Region, and drains to Lake Tana, Ethiopia's largest lake. It is situated $625 \mathrm{~km}$ north of Addis Ababa (60 km from the town of Bahir Dar, capital of the Amhara region) and has a total drainage area of approximately $1,272 \mathrm{~km}^{2}$. The main river has a length of around $129.7 \mathrm{~km}$. The area's geographical coordinates are $12^{\circ} 35^{\prime}$ North, $41^{\circ} 25^{\prime}$ East, $13^{\circ} 54$ 'N and $35^{\circ} \mathrm{E}$. Ethiopia's largest river basin and the study area map are shown in (Figure 1) below.

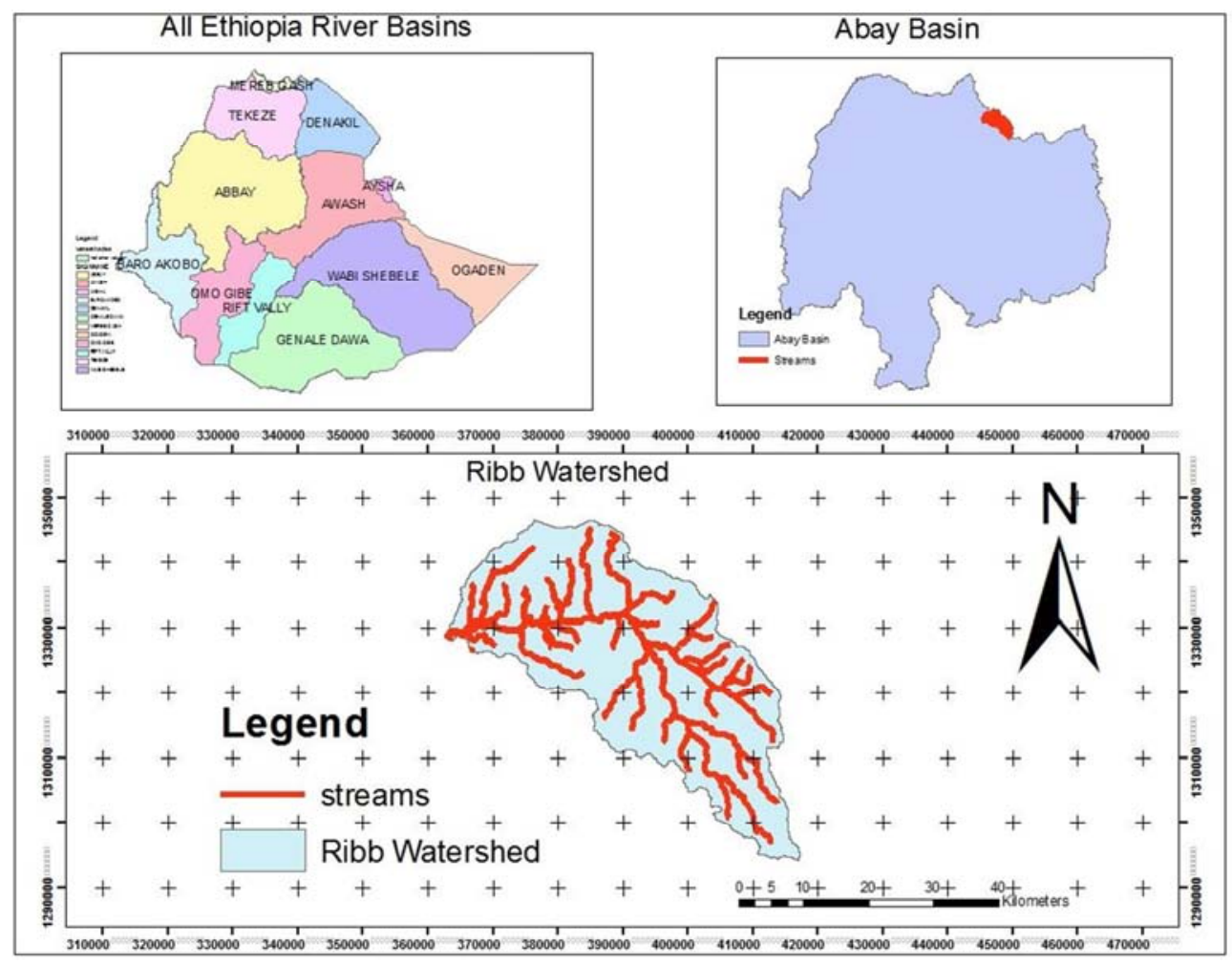

Figure 1. The major river basin of Ethiopia and the study area map.

\section{Materials Used}

Some equipment, materials and software for data collection, processing and evaluation are needed for proper implementation of the report. Some of the software and materials needed for this analysis include; Arc-GIS 9.3 for the acquisition of hydrological and physical parameters and spatial data of the study area catchments, Soil and Water Assessment Tool (SWAT2009) software, Hydrological Data
(Daily Discharge) and Sediment Concentration, GPS Meteorological Data, Land Use/Land Cover Data, Soil Data, Dew02, SWAT-CUP and Excel Spreads Concentration etc.

Data Collection and Analysis

Through using two key categories of data collection techniques, such as the primary data field and the collection of secondary data, different data collection methods have been used to collect the requisite data, materials and 
information. Different organizations obtained the necessary hydro-meteorological data, DEM, land use map and soil map. SWAT also requires long-term climate data on a regular basis to model hydrological processes. The required climate data was collected from the National Meteorological Services Agency (NMSA) for this particular study. As a weather generator station, the first class Debretabor station, which has all the components of climate variables listed above, was used. In and around the catchment, data on precipitation, maximum and minimum temperatures, sunshine hours, relative humidity, and wind speed were collected from four meteorological stations (Debretabor, Addiszemen, Woreta and Ageregenet).

\section{Land Use/Land Cover Map}

Land use is one of the most significant factors affecting a catchment's runoff, evapotranspiration, and surface erosion. The map of land use/land cover gives the spatial extent and classification of the study area's different land use/land cover groups. The hydrological characteristics of the basin or study area are produced by the land use cover data combined with the soil cover data, which in turn determines the excess precipitation, the recharge to the groundwater system and the storage in the soil layers. Data on land use was collected from Ethiopia's Ministry of Water, Irrigation and Electricity.

\section{Soil Data}

The soil data required by Arc SWAT to predict stream flow and sediment yield should include the necessary inputs relating to the physical and chemical properties of the soil catchment. First the soil type distribution shape file format was obtained from the Ministry of Water, Irrigation and Energy via the catchment [10]. Chromic Luvisols, Eutric Fluvisols, Eutric Leptisols, Haplic Nitisols and Urban are major soil of the study region. The soil texture, usable water content, hydraulic conductivity, bulk density and organic carbon content for various layers of each soil type were extracted from the major soils of the World Database and the World Database Digital Soil Map using this shape file. The main soil types of the study area are shown in (Figure 2) and
(Table 1).

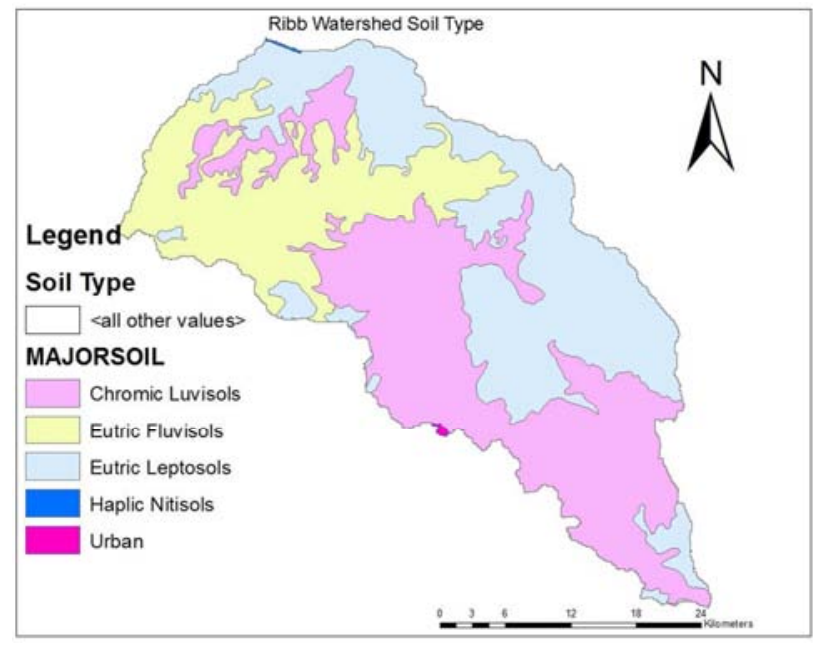

Figure 2. Soil map of the study area.

Table 1. Major soil types of the study area.

\begin{tabular}{llll}
\hline S/No & Soil Type & Area Km2 & \% \\
\hline 1 & Chromic Luvisols & 503.5 & 39.6 \\
2 & Eutric Fluvisols & 303.3 & 23.8 \\
3 & Eutric Leptisols & 463.9 & 36.5 \\
4 & Haplic Nitisols & 0.76 & 0.005 \\
5 & Urban & 1 & 0.008 \\
\hline
\end{tabular}

\section{River Discharge and Sediment yield}

The regular river discharge and sediment concentration values for the Ribb River were obtained from the Ministry of Water, Irrigation and Energy Hydrology Department [11] Ethiopia. For model calibration and validation, these regular river discharges and sediment concentrations at the Ribb River have been used. For one station in between (Addiszemen and Woreta towns), data on river discharge and sediment concentration was available. The station, although they have missing details, has discharge data from 1994 to 2014. The description of the stream flow data and the percentage of the data missing are given in (Table 2).

Table 2. Summary of available flow data with percent of missing.

\begin{tabular}{llllll}
\hline Station & X-Coordinate & Y-Coordinate & Elevation & Length of data Used & Percent of Missing data (\%) \\
\hline Ribb & 359551 & 1325931 & 1798 & $1994-2014$ & 7.13 \\
\hline
\end{tabular}

\section{Rating Curve}

To build the rating curve, the available sediment concentration data was converted to sediment load. The graphical representation of flow versus sediment load is the Rating Curve. From the discharge and sediment concentration, the sediment load is determined as follows in (Figure 3).

$$
S=86.4 * Q * C
$$

Where: $\mathrm{S}=$ sediment load (ton/day), $\mathrm{Q}=$ discharge $\left(\mathrm{m}^{3} / \mathrm{s}\right)$, $\mathrm{C}=$ sediment concentration $\left(\mathrm{kg} / \mathrm{m}^{3}\right)$

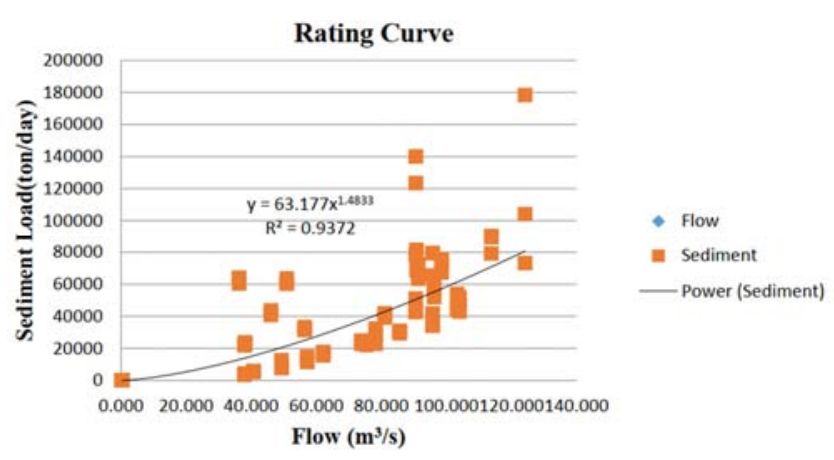

Figure 3. Rating curve of flow versus sediment load. 


\section{Field Observation}

In the selected Ribb Sub-catchment, preliminary reconnaissance was performed. Visual observations were made during fieldwork via transect walks along selected routes for the identification of surface characteristics and forms of land use and key knowledge interviews and group discussions were held. In order to complement other data sources, focus group discussion was used. Field work was also carried out by collecting GPS data for ground-truth verification of mapped features. The GPS was used to obtain geo-referencing coordinates for satellite photos, aerial images, and to check the accuracy of classified satellite images. Hydro-meteorological gauging stations were observed during field work. At the gauging station, the total flow of a river was evaluated, which shows field observation of the study area, capturing all the flow from all the upper ones in subcatchment (Figure 4 (A, B, C, D,)).

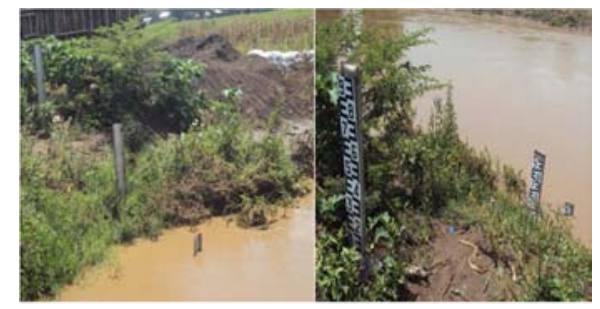

A, Gauging station

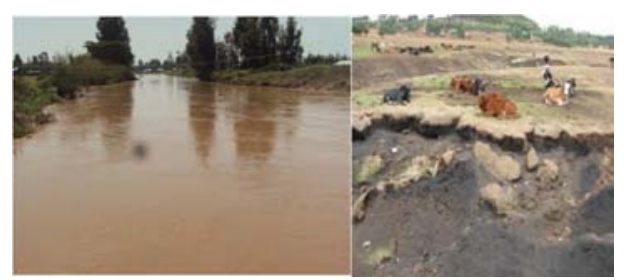

B, River flow C, Uncontrolled/ Overgrazed land leading to land degradation

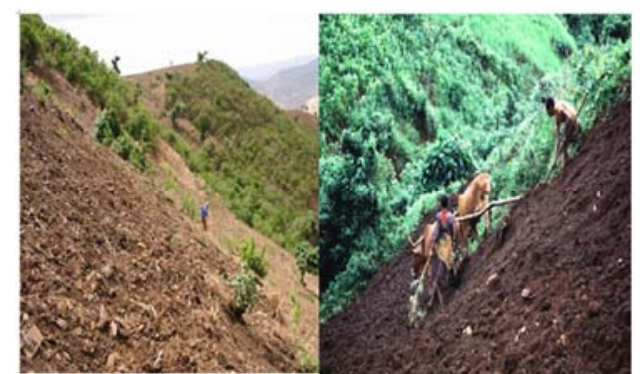

D, Deforestation practices for cultivation ultimately leading to severe soil erosion

Figure 4. Field observation

\section{Hydrological Model Selection Criteria}

There are different parameters that can be used to choose the right hydrologic model. Since every project has its own unique specifications, these standards are often projectdependent. There are four common, fundamental criteria among the various selection criteria that must always be addressed [12].

Description of SWAT Model

SWAT is a basin-scale model constructed within a watershed to simulate hydrological processes, nutrient cycles, and sediment transport [13]. SWAT divides the watershed into sub watersheds based on drainage areas of the tributaries to simulate hydrological procedures in a watershed. [14]. Depending on land use and land cover, soil and slope features, the sub watersheds are further subdivided into smaller spatial modeling units known as HRUs [15].

A land stage and a water routing process consist of the SWAT hydrological compartment in a watershed. The hydrological cycle land process regulates the amount of water, sediment, nutrient and pesticide loadings in each subwatershed to the main channel [16]. The flow of water, sediment and agricultural chemicals through the channel network to the watershed outlet is considered during the routing stage [17].

There are eight key components of the model: hydrology, weather, sedimentation, soil temperature, crop growth, nutrients, pesticides, and farm management [18]. However the following subsections present a brief overview of some of the SWAT computing procedures considered in this report. Four key phases of ArcSWAT preprocessing: Watershed Delineation, Hydrologic Response Unit (HRU) Analysis, Weather Data Classification and SWAT simulation, including sensitivity and calibration analysis [19].

To understand how each segment functions in the modeling process, it is necessary to understand the conceptual structure of each step, what knowledge is used and how it is incorporated into Arc SWAT [20] figure 5 below displays the modeling flow chart using arc SWAT.

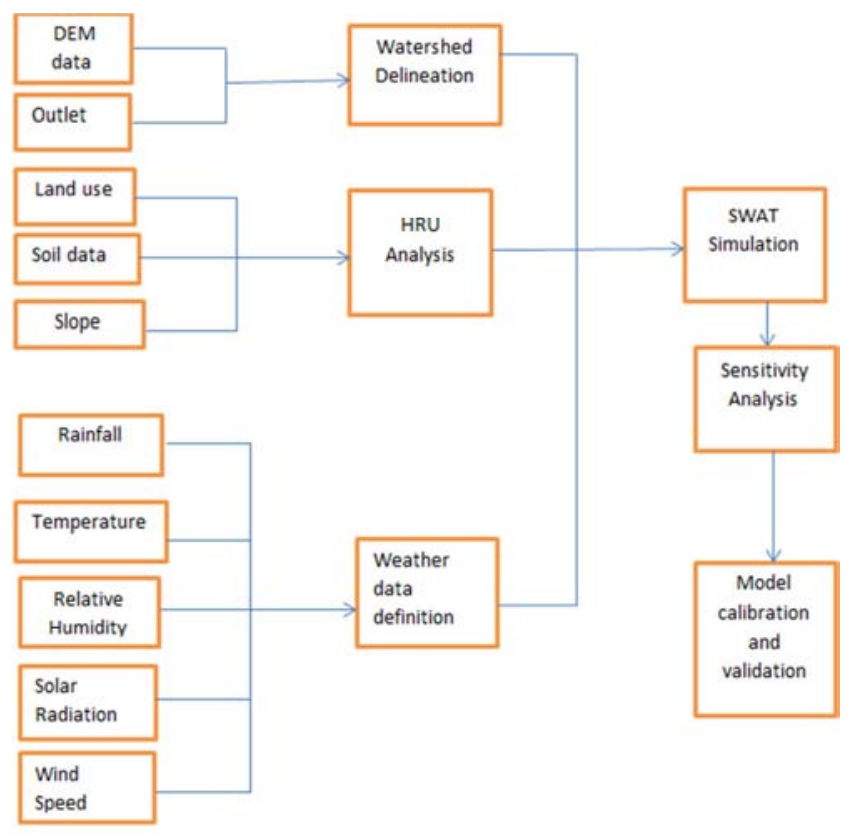

Figure 5. Conceptual frame work showing ARC SWAT Processes.

\section{SWAT CUP}

For SWAT, SWAT CUP is an interface that has been developed. Any calibration or sensitivity software can be connected easily to SWAT using this generic interface [21]. The software connects GLUE, Parasol, SUFI2, and MCMC 
processes to SWAT to illustrate this. The use of sequential uncertainty fittings (SUFI2) was favored in this particular study [22]. Automated model calibration involves manually modifying unknown model parameters, running the model, and extracting the necessary outputs (corresponding to measured data) from the model output files [23]. An interface's main purpose is to provide a link between the interfaces a calibration software and the model input/output [24].

The watershed sub-basins are split into 183 multiple Hydrologic Response Units (HRUs). The HRUs reflect areas with homogeneous features of land use/covering, management, and soil. However in SWAT simulation, they have no separate spatial representation [25]. The HRU is spatially implicit in SWAT, with its exact location on the surface it is impossible to classify and the same HRU may cover multiple locations in a sub-basin [26]. Each HRU in a sub watershed is responsible for loadings of flow, sediment, nutrients, and pesticides that are diverted to the watershed outlet through rivers, ponds, and/or reservoirs. You can find detailed explanations of the components of the platform and model in [27]. The SWAT model involves the formation of Hydrologic Response Units (HRUs), which are the specific combinations within each sub-basin of land use, soil and slop type shown in figure 6 below.

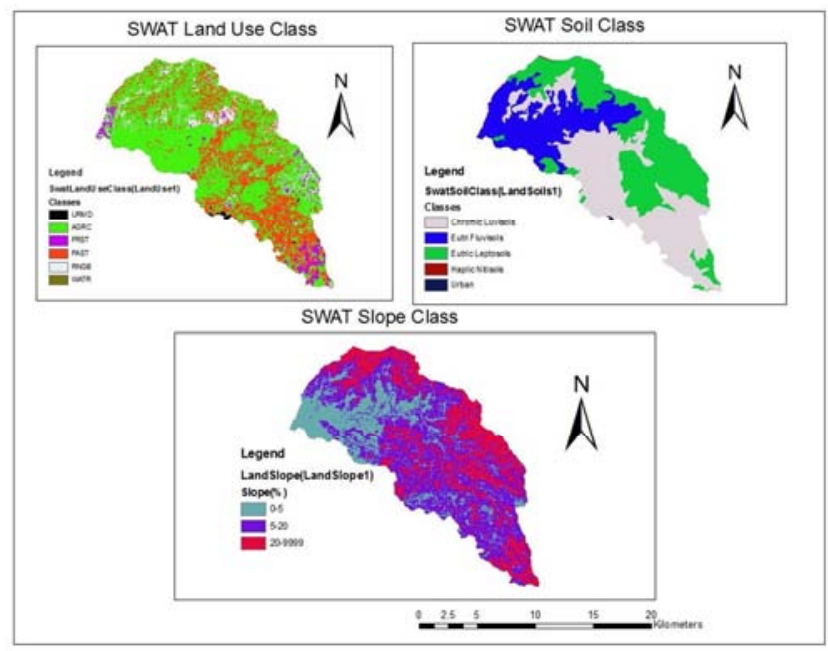

Figure 6. Reclassified land use, soil and slope of rib watershed.

\section{SWAT Simulation}

Database files containing the information necessary to generate the default SWAT model input have been generated. In SWAT, the appropriate parameter values can be entered and modified manually once the default input database files are created [28]. Where appropriate, the land use land cover parameters were edited. The SWAT simulation run was conducted on climate data from 1994-2014. Data for two years was maintained as a warm up time. To make sure that there are no effects from the initial conditions in the model, the warm-up period is significant. Warm-up cycle lengths vary from catchment to catchment [29].

Sensitivity Analysis

In examining the type of error that occurs in simulated variables, parameters other than those found during sensitivity analysis have been updated [30]. Sensitivity analysis is therefore useful not only for model creation, but also for model validation and uncertainty reduction, as a method for evaluating input parameters with regard to their effect on model performance [31].

Table 3. Parameter sensitivity classes (Lenhart et al., 2000).

\begin{tabular}{lll}
\hline Sensitivity class & Index & Sensitivity \\
\hline I & $<0.05$ & Small to negligible \\
II & $0.05=<\mathrm{I}=<0.2$ & medium \\
III & $0.2=<\mathrm{I}=<1$ & High \\
IV & $\mathrm{I}>1$ & Very high \\
\hline
\end{tabular}

\section{Model Calibration and Validation}

As data for calibration and validation for the SWAT model, the time series of discharge at the catchment outlet was used the model was calibrated using the measured stream flow data from 1994 to 2014, and first the critical parameters that control the watershed were obtained and ranked according to their sensitivity.

\section{Results and Discussion}

\section{Land Use/Land Cover Map}

One of the most important factors affecting runoff, evapotranspiration and surface erosion in a water shed is land use [32]. Data collected from the ground truth during fieldwork and fieldwork the catchment has numerous land use/land cover groups obtained from the Ministry of Water, Irrigation and Energy in the 2008 land use/land cover map. In recent decades, forest cover, grass land, shrub land; from the catchment area have been converted into agricultural or cultivated land. This transition may be attributed to high growth in the population. The land use map was reclassified to reflect land use according to specific types of land use such as agricultural land, grass land, shrub land, forest land, water body and built-up area. The 2008 land cover map (Figure 7) shows that approximately $61.4 \%$ of the Ribb catchment was covered by agricultural land, $28.1 \%$ by grass land, $4 \%$ by forest land, $6.1 \%$ by shrub and bush land, $0.4 \%$ by urban settlement area, and $0.01 \%$ by water body.

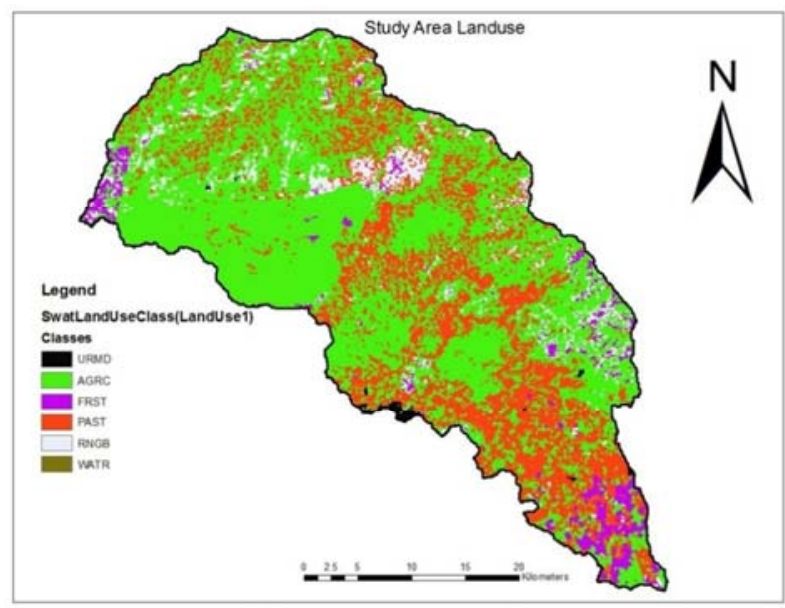

Figure 7. Land use Land cover map of Ribb watershed (2008). 
The real percentages covered by various forms of land use cover in 2008 are presented in the following (Table 4).

Table 4. Area covered by different land use land cover type.

\begin{tabular}{llll}
\hline No & Land use type & Area $\mathbf{k m}^{\mathbf{2}}$ & $\mathbf{( \% )}$ \\
\hline 1 & Cultivated land & 781 & 61.4 \\
2 & Grass land & 358 & 28.1 \\
3 & Forest land & 51 & 4 \\
4 & Shrub and Bush land & 78 & 6.1 \\
5 & Water body & 0.14 & 0.01 \\
6 & Built up area & 5 & 0.4 \\
\hline
\end{tabular}

Flow Sensitivity Analysis

A stream flow sensitivity analysis was performed on model parameters after the SWAT model for the Ribb river watershed was run using the SWAT interface. This was done to decide the parameters that affect the modeled stream flow [33]. To prevent problems known as over parameterization, it is important to define sensitive parameters for a model [34]. The sensitivity analysis was conducted for the period 19942014 using the SWAT gui 270 iterations were conducted during the sensitivity analysis and 27 parameters were tested for flow sensitivity analysis, but 7 parameters were found to be the most sensitive with their effect on the simulated result when their value was adjusted and calibration was chosen. The most sensitive parameter for flow was curve number II (CN2) is presented in the following (Table 5).

Table 5. SWAT parameters selected for flow calibration based on sensitivity analysis.

\begin{tabular}{|c|c|c|c|c|c|}
\hline Parameter & Description & Mini value & Maxi value & Fitted value & Sensitivity Rank \\
\hline $\mathrm{CN} 2$ & SCN curve number & 35 & 98 & 40.229 & 1 \\
\hline SOL_AWC & soil available water capacity & 0 & 1 & 0.661 & 2 \\
\hline $\mathrm{SOL} Z \mathrm{Z}^{-}$ & Soil Depth & 0 & 3000 & 1539 & 3 \\
\hline GWQMN & Threshold water depth in the shallow aquifer for flow & 0 & 5000 & 1555 & 4 \\
\hline ESCO & Soil Evaporation & 0 & 1 & 0.905 & 5 \\
\hline REVAPMN & Compensation Factor & 0 & 500 & 230.5 & 6 \\
\hline ALPHA_BF & Base flow alpha factor & 0 & 1 & 0.623 & 7 \\
\hline
\end{tabular}

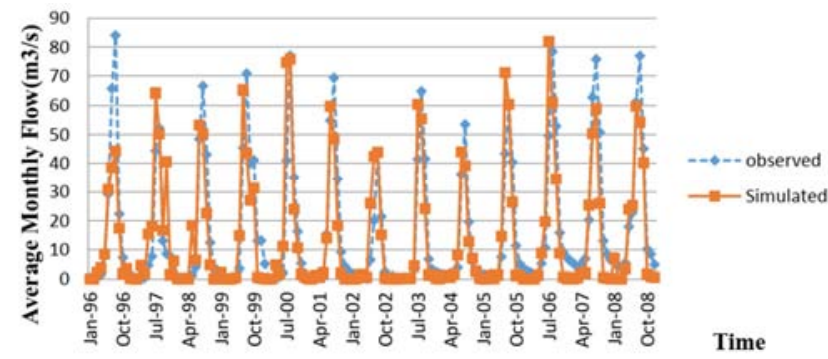

Figure 8. Average Monthly Observed and Simulated Flow Calibration (1996 $-2008)$.

\section{Stream Flow Calibration Analysis}

After the identification of critical parameters, calibration followed by validation for the significant parameters was performed [23]. In addition to the manual calibration technique for catchment, model calibration was performed to test the efficiency of model simulation using automated calibration tools embedded in SWAT [35]. Since manual calibration gives a better result on fitting the parameters of simulated and observed flow, it was utilized following to the auto calibration. Initially it was carried out using the most sensitive parameters and the best parameter value which were resulted from sensitivity analysis. The most influential parameters were found among the 27 parameters resulting from the sensitivity analysis method of SCN curve number (CN), Soil Evaporation Compensation Factor (ESCO), Soil Depth (m) (Sol-Z), Threshold water depth in the shallow flow aquifer (GWQMN), Base flow alpha factor (Alpha-Bf), (REVAPMN) and Soil Accessible Water Potential (SOLAWC) and were used for further calibration. These were the significant parameters to match when altering the data. Most models are equipped with parameter default values. In this case, however the initial values of the model parameters have been specified. Based on relevant previous works and literature, minimum and maximum appropriate values have been given. By varying the values of the critical parameters within their permissible values, manual calibration was performed. By modifying one of the more sensitive parameters in the model and then observing the resulting changes in the simulated flow, it was performed repeatedly.

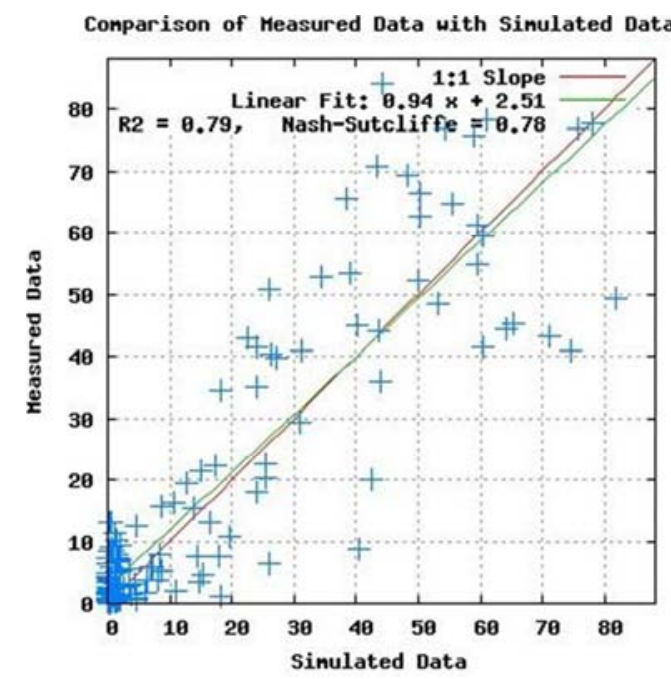

Figure 9. Scatters plot of Observed Vs Simulated Flow for calibration (1996 $-2008)$.

The parameters calibrated are within the range of SWAT's suggested values. The model was run after the calibration outcome, and the simulated flow was compared with the observed flow. The hydrographs of the observed and simulated flows from 01 January 1996 to 31 December 2008 and the twoyear warm-up period for the calibration process are shown below (Figure 8). The calibration cycle showed a strong agreement between the measured and simulated monthly flows. 
The outcome of the calibration showed that the determination coefficient $\left(\mathrm{R}^{2}\right)$ and the Nash-Sutcliffe Efficiency (NSE) were respectively 0.79 and 0.78 . A fair linear correlation between the two data sets was also shown by the Web scatter plot of the calculated values and the simulated monthly stream flow data (Figure 9). Scatters plot for calibration of Observed Vs Simulated Flow (1996-2008). The performance of the model is calculated by the water balance, which is the combined discharge comparison of the simulated and observed discharge (Figure 10), in addition to the R2 and NSE.

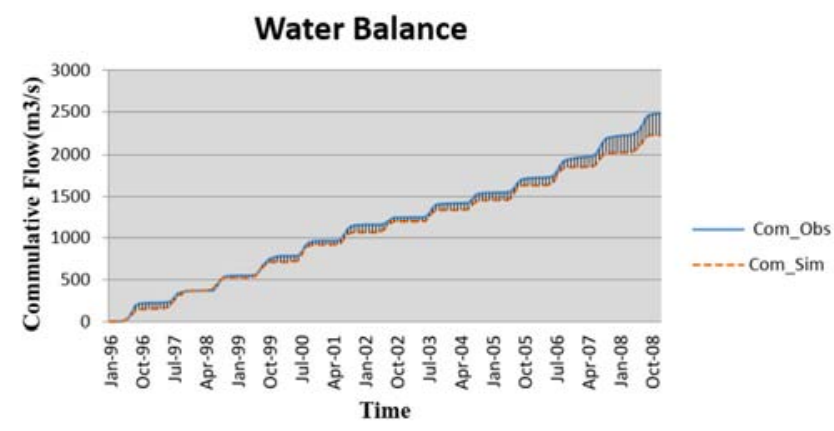

Figure 10. Cumulative simulated and observed discharges for the calibration period.

\section{Stream Flow Validation Analysis}

To understand the degree of certainty of the model prediction, the validation process using an independent collection of observed data is important [36]. Model performance may not be comparable in the calibration and validation cycles. Recent studies have shown that there are a variety of climate model validity problems. This is due to the uncertainty of the uncertainties of the modeling dataset based on the existence of environment and time. Another explanation is that the hydrologic condition during the calibration phase could not be the same during the validation period as the hydrologic condition. Using calibrated parameters, the validation was carried out. The remaining observed stream flow data from the Ribb River from 2009 to 2014 was used for model validation. In the validation process, without any modifications, the model was run with input parameters set during the calibration process. A strong agreement between the monthly measured and simulated flows figures has also been shown in the validation cycle (figure 11). The validation result showed that the coefficient of determinations $\left(\mathrm{R}^{2}\right)$ and the Nash-Sutcliffe Efficiency (NSE) are 0.7 and 0.68 respectively. In general, a strong correlation and agreement between the monthly measured and simulated flows was suggested by the model performance evaluation. A fair linear association between the two datasets was also seen in the dispersion plot of the calculated values and the simulated monthly stream flow data (Figure 12). In addition to the R2 and NSE, the model's efficiency is calculated by the water balance, which is 13 percent more than predicted by the combined discharge comparison of simulated and observed discharge (Figure 13).

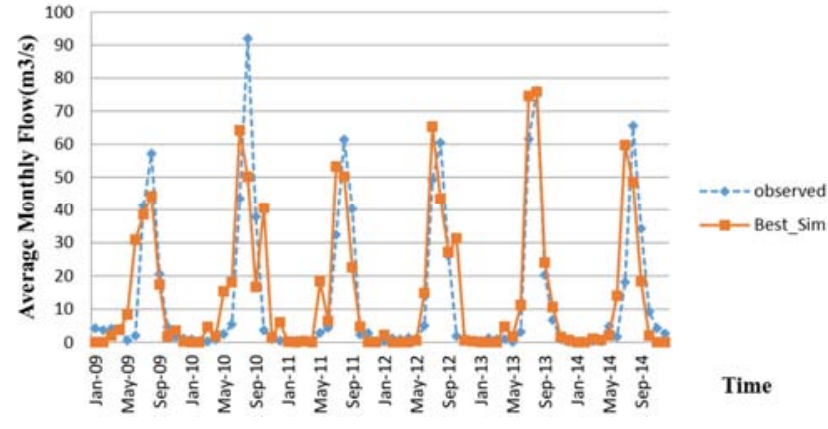

Figure 11. Average Monthly Observed and Simulated Flow Validation (2009 $-2014)$.

Conparison of Measured Data with Sinulated Data

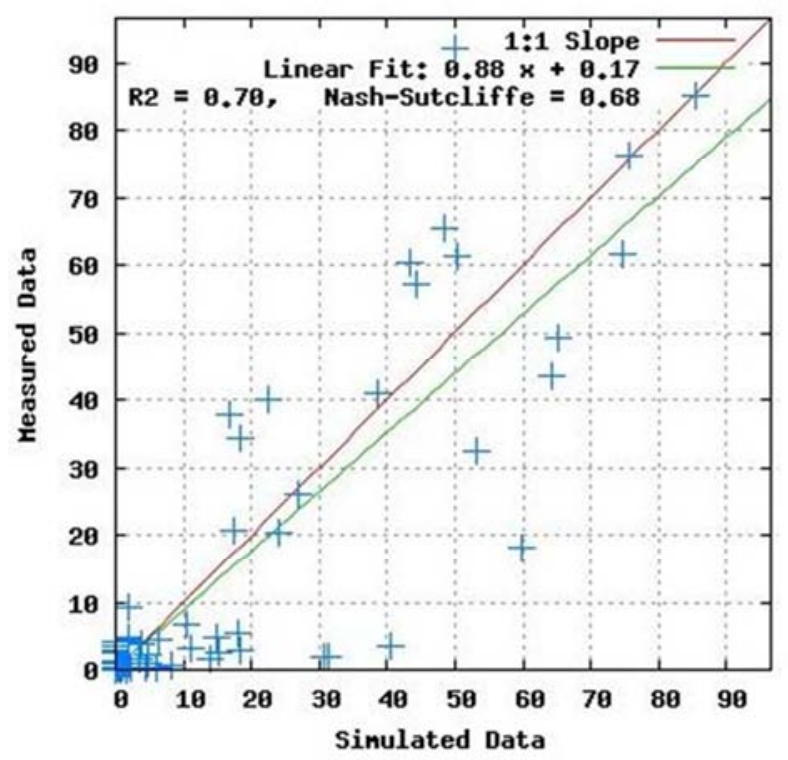

Figure 12. Scatter plots of Observed Vs Simulated Flow for Validation (2009 $-2014)$.

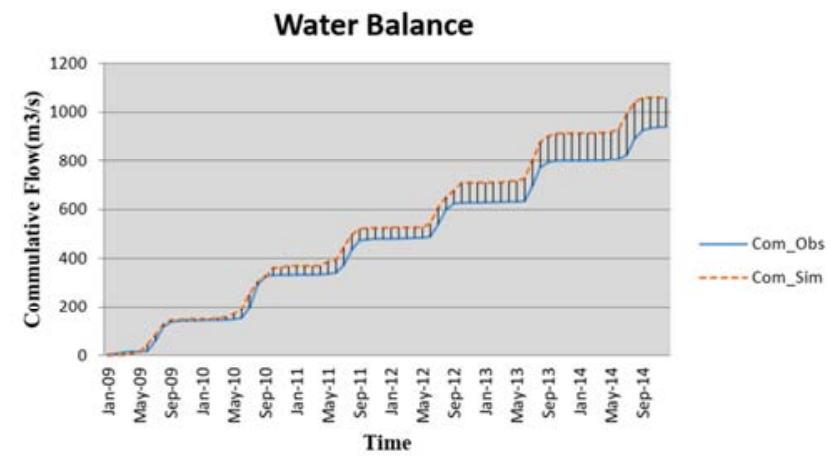

Figure 13. Cumulative of simulated and observed discharges for the Validation period.

Table 6. Summery of the Calibration and Validation period, $R^{2}$ and NSE.

\begin{tabular}{llll}
\hline & Period & $\mathbf{R}^{\mathbf{2}}$ & NSE \\
\hline Calibration & $1996-2008$ & 0.79 & 0.78 \\
Validation & $2009-2014$ & 0.70 & 0.68 \\
\hline
\end{tabular}

Sediment Yield Sensitivity Analysis

Once the flow has been correctly described by the model, the emphasis is transferred to the model for sediment 
calibration and validation. This includes altering the parameters within the model that govern the generation of sediment. For the sensitivity analysis conducted using the SWAT interface for the period 1994-2014, the sediment parameters used for calibration and validation were chosen. During the sensitivity analysis, 60 sediment iterations were performed and 6 sediment sensitivity analysis parameters were tested. When their value was adjusted and selected for calibration, 6 of the sediment parameters were sensitive because of their effect on the simulated outcome. The most sensitive parameter for sediment was USLE equation support practice (USLE P).

Table 7. SWAT parameters selected for sediment yield calibration based on Sensitivity.

\begin{tabular}{|c|c|c|c|c|c|}
\hline Parameter name & Description & Mini value & Maxi value & Fitted value & Sensitivity Rank \\
\hline USLE_P & USLE equation support practice & 0 & 1 & 0.990 & 1 \\
\hline CH_COV1 & Channel cover factor & 0 & 1 & 0.381 & 2 \\
\hline CH_EROD & channel erodiability factor & 0 & 1 & 0.168 & 3 \\
\hline MO_SPCON & Linear parameter for maximum sediment yield & 0.0001 & 0.01 & 0.001 & 4 \\
\hline SPEXP & $\begin{array}{l}\text { Exponential parameter for maximum sediment yield in channel } \\
\text { sediment routing }\end{array}$ & 1 & 2 & 1.618 & 5 \\
\hline USLE C & Cropping practice factor & 0 & 1 & 0.820 & 6 \\
\hline
\end{tabular}

\section{Sediment Calibration}

Once the sediment parameter values are established through use of the manual calibration within Arc SWAT, all the 6 parameters which resulted from sensitivity analysis USLE equation support practice (USLE_P), Linear parameter for maximum sediment yield (SPCON), Exponential parameter for maximum sediment yield in channel sediment routing (SPEXP), Cropping practice factor (USLE_C), channel cover actor ( $\mathrm{CH}$ _COV1), channel erodiability factor (CH_ERODMO) were found the most influential parameters and were used for further calibration. By varying the values of the critical parameters within their permissible values, manual calibration was performed. It was repeatedly carried out by adjusting one of the model's more sensitive parameters and then analyzing the resulting changes in the simulated sediment. The parameters calibrated are within the range of SWAT's suggested values.

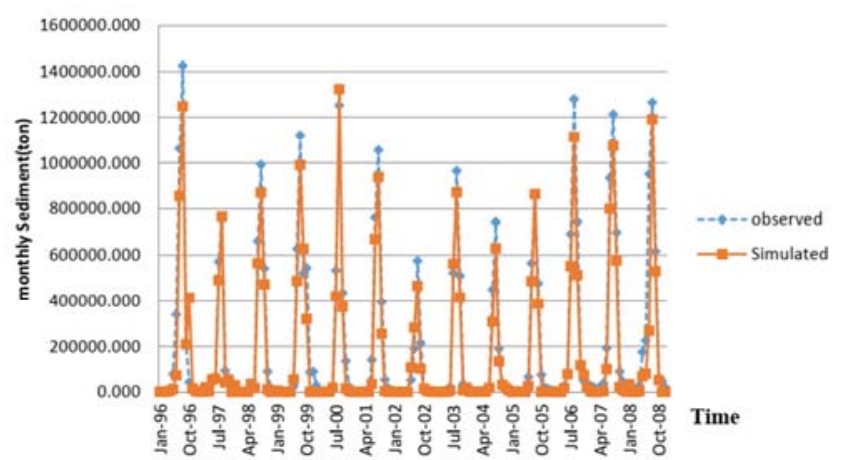

Figure 14. Monthly Measured and Simulated Sediment Yield for Calibration (1996-2008).

After the calibration result, the simulated sediment was compared with the sediment yield observed (Figure 14) below the hydrographs of the sediment observed and simulated from 1996 to 2008 and two years for the calibration process such as flow warm-up time. The calibration cycle has shown a strong agreement between the monthly sediment yield calculated and simulated. The result of the calibration showed that the determination coefficient $\left(\mathrm{R}^{2}\right)$ and the Nash-Sutcliffe Efficiency (NSE) were respectively 0.77 and 0.71 . A fair linear correlation between the two data sets was also seen in the Web dispersion plot of the calculated values and the simulated monthly sediment yield (Figure 15).

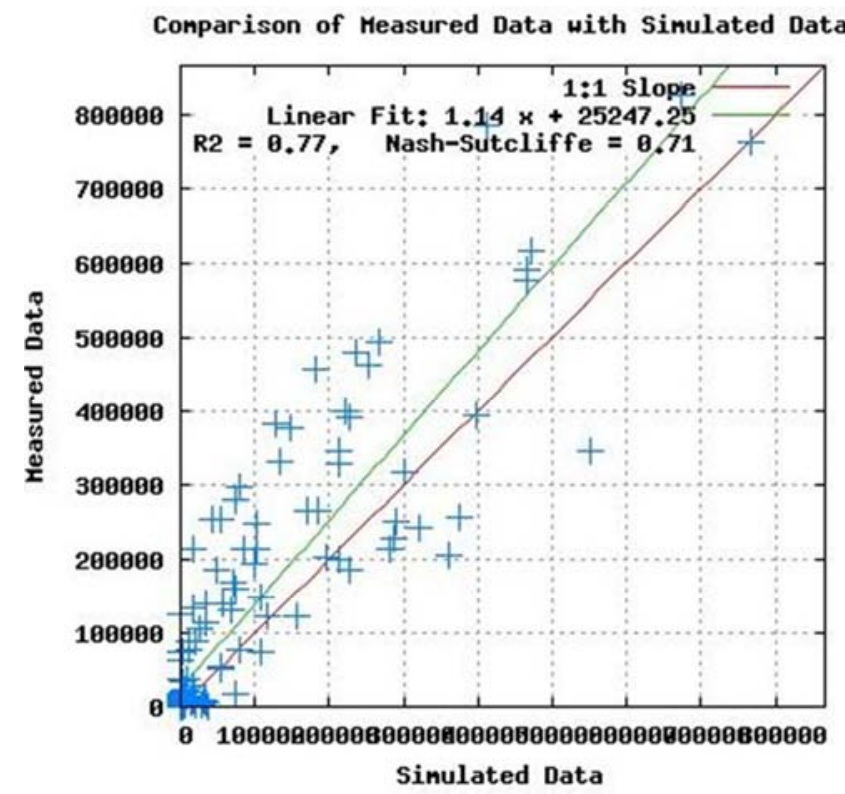

Figure 15. Scatter plot of observed Vs simulated sediment yield for calibration (1996-2008).

\section{Sediment Yield Validation}

Sediment yield validation was also carried out to understand the degree of confidence of the model estimation using an independent collection of observed results. Using calibrated parameters, the validation was carried out. The remaining observed sediment data from the Ribb River from 2009 to 2014 was used for model validation. A strong agreement between the monthly measured and simulated flows has also been shown in the validation period (Figure 16). The validation result showed that the determination coefficient $\left(\mathrm{R}^{2}\right)$ and the Nash-Sutcliffe Efficiency (NSE) are respectively 0.72 and 0.72 . In general, a strong correlation and agreement between the monthly measured and simulated flows was suggested by the model performance evaluation. A fair linear association between the two datasets has also been 
shown by the scatter plot of the measured values and the simulated monthly sediment yield (Figure 17).

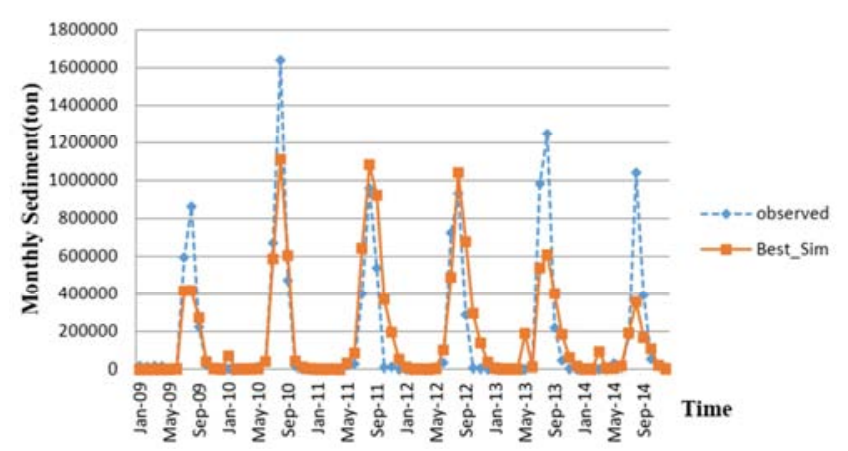

Figure 16. Monthly Measured and Simulated Sediment Yield for validation (2009-2014).

Conparison of Measured Data with Sinulated Data

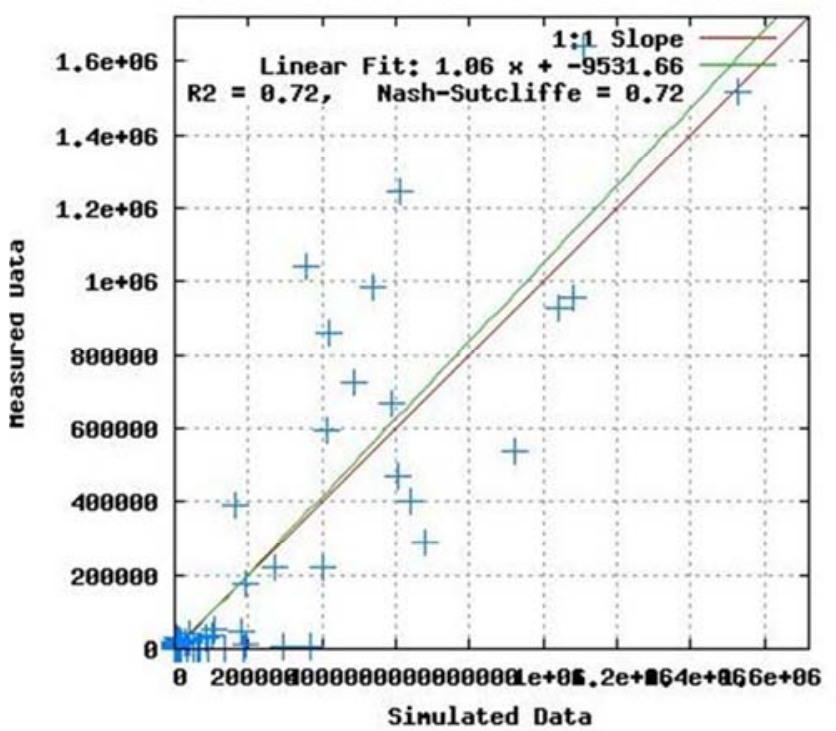

Land use/land cover change scenario analysis on hydrological processes

To examine the effect of land cover changes on the hydrological regime, three land use/cover change scenarios are developed. Base scenario: current patterns of land use, scenario1: completely modified shrub and bush lands to forested land and scenario2: completely changed grass land to agricultural land.

Base scenario: current land use practices

When interpreting the hydrological consequences of other management situations, it provides a reference point or baseline data. In order to examine the impacts on hydrological responses, this scenario uses the current land use land cover forms. The analyzed consequence of this scenario shows that during the rainy season of August, the average minimum monthly stream flow of $1.23 \mathrm{~m}^{3} / \mathrm{s}$ occurs in February and the average maximum stream flow of $128.14 \mathrm{~m}^{3} / \mathrm{s}$ and the maximum monthly sediment yield at the outlet of the watershed is 13114300 tones during August and the minimum is 19739.846 tones per month.

Scenario 1: Shrub and Bush Lands Completely Changed to Forest Land

In this scenario of land use transition, more emphasis is put on protecting existing forests from deforestation and developing new forest land by substituting shrub and bush land. The results of this scenario show that, relative to the base period, the scenario had a trend of similar stream flow to the base scenario (Table 8), but a shift in sediment yields (Table 9). Due to the reduced slopes, soil and water management steps and afforestation from the upstream, the reduction of sediment yield during the wet season can be achieved.

Scenario 2: Grass Lands Completely Changed to Cultivated Land

Figure 17. Scatter plot of observed Vs simulated sediment yield for validation (2009-2014).

Table 8. Average Monthly flows of Different Land Use Scenarios.

\begin{tabular}{llllll}
\hline Month & Base Scenario $\left(\mathbf{m}^{3} / \mathbf{s}\right)$ & Scenario1 $\left(\mathbf{m}^{3} / \mathbf{s}\right)$ & Scenario2 $\left(\mathbf{m}^{3} / \mathbf{s}\right)$ & Scenario1-Base Scenario $\left(\mathbf{m}^{3} / \mathbf{s}\right)$ & Scenario-Base Scenario $\left(\mathbf{m}^{3} / \mathbf{s}\right)$ \\
\hline 1 & 5.118 & 5.216 & 5.649 & 0.098 & 0.531 \\
2 & 1.227 & 1.260 & 1.387 & 0.032 & 0.160 \\
3 & 2.219 & 2.271 & 2.510 & 0.052 & 0.290 \\
4 & 2.463 & 2.536 & 2.632 & 0.073 & 0.169 \\
5 & 8.667 & 8.872 & 8.953 & 0.205 & 0.286 \\
6 & 22.076 & 22.507 & 23.373 & 0.432 & 1.297 \\
7 & 89.051 & 89.835 & 92.559 & 0.784 & 3.508 \\
8 & 128.140 & 129.006 & 130.892 & 0.865 & 2.751 \\
9 & 107.069 & 107.829 & 108.125 & 0.760 & 1.056 \\
10 & 65.711 & 66.259 & 66.384 & 0.548 & 0.673 \\
11 & 34.042 & 34.387 & 34.769 & 0.344 & 0.727 \\
12 & 15.553 & 15.759 & 16.269 & 0.206 & 0.715 \\
Annually & 40.111 & 40.478 & 41.125 & 0.367 \\
\hline
\end{tabular}


Table 9. Monthly Sediment Yields of Different Land Use Scenarios.

\begin{tabular}{llllll}
\hline Month & Base scenario (ton) & scenario1 (ton) & Scenario2 (ton) & scenario1 -base scenario (ton) & Scenario2 - base scenario (ton) \\
\hline 1 & 616535 & 616932.3 & 888716 & 397.3 & 272181 \\
2 & 19739.85 & 19961.06 & 29150.14 & 221.209 & 9410.289 \\
3 & 161581.5 & 162095.8 & 231490.2 & 514.3004 & 69908.67 \\
4 & 8206.619 & 8415.776 & 10960.51 & 209.157 & 2753.893 \\
5 & 206452.2 & 206390.5 & 276384.2 & -61.67 & 69932.05 \\
6 & 1734226 & 1732717 & 2482302 & -1509 & 748076 \\
7 & 10750300 & 10740300 & 15589000 & -10000 & 4838700 \\
8 & 13114300 & 13103200 & 18989100 & -11100 & 5874800 \\
9 & 6333890 & 6332400 & 9164260 & -1490 & 2830370 \\
10 & 1254246 & 1254014 & 1759359 & -232 & 505113 \\
11 & 374744 & 375448 & 517503 & 704 & 142759 \\
12 & 60669 & 61101.4 & 77478.3 & 432.4 & 16809.3 \\
Annually & 34634890 & 34612976 & 50015703 & -21914.3 & 15380813 \\
\hline
\end{tabular}

The study published by the Ethiopian Climate Resilient Green Economy Strategic Plan (CRGE, 2011) of the Ministry of Finance and Economy and the Government's Green Economy Strategy and Strategies (Ethiopian Climate Resilient Green Economy Strategic Plan (Ethiopian Climate Resilient Green Economy Strategic Plan shows that over the last five years, 15 percent expansion of agricultural land and 3 percent re-forestation work accounted for growth in the agricultural sector. The conversion of grass land and bare land to agricultural practices has been considered. The outcome of this scenario indicates that stream flow does not vary significantly from the base scenario that is increased annually by $1.01 \mathrm{~m}^{3} / \mathrm{s}$ and a substantial increase in sediment yield of 15380813 tones can be observed annually due to the expansion of agricultural land. However, the trends of the two graphs are similar despite the value difference at each month. The reduction in stream flow during the dry season can be explained by considering the increase of irrigation agriculture and water supply for domestic use from the upstream.

A significant characteristic in the runoff phase that affects infiltration, interception, erosion, and evapotranspiration is land use/cover change. In current hydrological conditions, these changes cause distinct problems. Changes in the form of land use in some areas, such as scenario 2 grass fields modified to agricultural land, would increase the volume of surface runoff, decrease the concentration time that causes many distractions by producing greater runoff and decrease the amount of water percolated into the soil. This reduces the amount of water to be recharged to the ground, and ultimately imbalances over all catchment hydrological conditions. The response of various hydrological components to different land uses is shown below (Table 10).

Table 10. Average annual values of different hydrological components of a watershed.

\begin{tabular}{|c|c|c|c|c|c|c|c|c|}
\hline Scenario & SURQ (mm) & LATQ (mm) & $\overline{\text { GWQ (mm) }}$ & ET $(\mathrm{mm})$ & PERC (mm) & TLOS S (mm) & WYLD (mm) & SEDYID (Ton/hr.) \\
\hline Scenario & 259.51 & 136.13 & 617 & 402 & 656.2 & 5.93 & 1006.2 & 14.489 \\
\hline Scenario1 & 259.53 & 137.23 & 625 & 392 & 664.76 & 5.93 & 1015.4 & 14.471 \\
\hline Scenario2 & 278.09 & 135.79 & 624 & 376 & 663.98 & 6.34 & 1031.6 & 21.146 \\
\hline
\end{tabular}

$\mathrm{ET}=$ Real evapotranspiration from $\mathrm{HRU}, \mathrm{SW}=$ Soil water material, $\mathrm{PERC}=$ water that percolates during the time step past the root region, $\mathrm{SURQ}=$ Surface runoff contribution to stream flow during the time step, TLOSS=Transmission losses, water lost in the HRU from tributary channels, transmission through the bed, $\mathrm{GW} Q=$ Ground water contribution to stream flow, LATQ=Lateral flow contribution to stream flow, WYLL=Lateral flow contribution to stream flow. In general, improvements in the form of land use of the region such as increasing the percentage of agricultural land increase surface runoff rate, promoting soil erosion, reducing the amount of water percolated to the soil. Increasing the percentage of forest land in turn raises the amount of water to be recharged into the soil, thus decreasing the potential for erosion due to reduced water velocity, which enables a higher degree of scouring. Therefore, hydrological responses are required to be updated or altered with agricultural expansion and human activity.

\section{Funding}

No funding.

\section{Conflicts of Interest}

The authors declare no conflict of interest.

\section{Acknowledgements}

The author would like to acknowledge the proof of flow, soil and land use / cover data from the Ethiopian Ministry of Water, Irrigation and Electricity and the National Meteorology Agency of Ethiopia for the provision of the required rainfall data and stream flow data. For his professional assistance in language and grammar editing, we also want to acknowledge Dr. Mulu Sewinet.

\section{References}

[1] Verburg PH, Kok K, Pontius RG, Veldkamp A. Modeling land-use and land-cover change. Land-use and land-cover change: Springer; 2006. p. 117-35.

[2] Haghighi AT, Darabi H, Shahedi K, Solaimani K, Kløve B. A scenario-based approach for assessing the hydrological impacts of land use and climate change in the Marboreh Watershed, Iran. Environmental Modeling \& Assessment. 2020; 25 (1): 41-57. 
[3] Turner BL, Meyer WB. Global land-use and land-cover change: an overview. Changes in land use and land cover: a global perspective. 1994; 4 (3).

[4] Schäfer MP, Dietrich O, Mbilinyi B. Streamflow and lake water level changes and their attributed causes in Eastern and Southern Africa: state of the art review. International Journal of Water Resources Development. 2016; 32 (6): 853-80.

[5] Genovese E. A methodological approach to land use-based flood damage assessment in urban areas: Prague case study. Technical EUR Reports, EUR. 2006; 22497.

[6] Rayner S, Lach D, Ingram H. Weather forecasts are for wimps why water resource managers do not use climate forecasts. Climatic change. 2005; 69 (2-3): 197-227.

[7] Woldesenbet TA, Diekkrüger B. Assessing Impacts of Land Use/Cover and Climate Changes on Hydrological Regime in the Headwater Region of the Upper Blue Nile River Basin, Ethiopia: Universität Leipzig; 2017.

[8] Boongaling CGK, Faustino-Eslava DV, Lansigan FP. Modeling land use change impacts on hydrology and the use of landscape metrics as tools for watershed management: The case of an ungauged catchment in the Philippines. Land use policy. 2018; 72: 116-28.

[9] REDA KW. HYDROLOGICAL RESPONSE TO LAND USE LAND COVER DYNAMICS AND SUB WATERSHED PRIORITIZATION FOR LAND AND WATER MANAGEMENT. 2015.

[10] Wang R. Modeling hydrologic and water quality responses to changing climate and land use/cover in the Wolf Bay Watershed, South Alabama 2010.

[11] Yasir S, Crosato A, Mohamed YA, Abdalla SH, Wright NG. Sediment balances in the Blue Nile River basin. International Journal of Sediment Research. 2014; 29 (3): 316-28

[12] Cunderlik JM, Burn DH. Non-stationary pooled flood frequency analysis. Journal of Hydrology. 2003; 276 (1-4): 210-23.

[13] Gassman PW, Sadeghi AM, Srinivasan R. Applications of the SWAT model special section: overview and insights. Journal of Environmental Quality. 2014; 43 (1): 1-8.

[14] Liu Y, Yang W, Wang X. Development of a SWAT extension module to simulate riparian wetland hydrologic processes at a watershed scale. Hydrological Processes: An International Journal. 2008; 22 (16): 2901-15.

[15] Welde K, Gebremariam B. Effect of land use land cover dynamics on hydrological response of watershed: Case study of Tekeze Dam watershed, northern Ethiopia. International Soil and Water Conservation Research. 2017; 5 (1): 1-16.

[16] Gevaert V, Van Griensven A, Holvoet K, Seuntjens P, Vanrolleghem PA. SWAT developments and recommendations for modelling agricultural pesticide mitigation measures in river basins. Hydrological sciences journal. 2008; 53 (5): 1075-89.

[17] Chaplot V. Impact of DEM mesh size and soil map scale on SWAT runoff, sediment, and NO3-N loads predictions. Journal of hydrology. 2005; 312 (1-4): 207-22.

[18] Arnold JG, Fohrer N. SWAT2000: current capabilities and research opportunities in applied watershed modelling.
Hydrological Processes: An International Journal. 2005; 19 (3): 563-72.

[19] Getachew HE, Melesse AM. The impact of land use change on the hydrology of the Angereb Watershed, Ethiopia. International Journal of Water Sciences. 2012; 1 (4).

[20] Di Luzio M, Srinivasan R, Arnold JG. Integration of Watershed Tools and Swat Model into Basins 1. JAWRA Journal of the American Water Resources Association. 2002; 38 (4): $1127-41$.

[21] Tejaswini V, Sathian K. Calibration and validation of swat model for Kunthipuzha basin using SUFI-2 algorithm. International Journal of Current Microbiology and Applied Sciences. 2018; 7 (1): 2162-72.

[22] Abbaspour KC. Swat-cup 2012. SWAT Calibration and uncertainty program - a user manual. 2013.

[23] Arnold JG, Moriasi DN, Gassman PW, Abbaspour KC, White MJ, Srinivasan R, et al. SWAT: Model use, calibration, and validation. Transactions of the ASABE. 2012; 55 (4): 1491508 .

[24] Zhang X, Beeson P, Link R, Manowitz D, Izaurralde RC, Sadeghi A, et al. Efficient multi-objective calibration of a computationally intensive hydrologic model with parallel computing software in Python. Environmental modelling \& software. 2013; 46: 208-18.

[25] Baker TJ, Miller SN. Using the Soil and Water Assessment Tool (SWAT) to assess land use impact on water resources in an East African watershed. Journal of hydrology. 2013; 486: $100-11$.

[26] Wang J, Ishidaira H, Sun W, Ning S. Development and interpretation of new sediment rating curve considering the effect of vegetation cover for Asian basins. The Scientific World Journal. 2013; 2013.

[27] Luo Y, Zhang M. Management-oriented sensitivity analysis for pesticide transport in watershed-scale water quality modeling using SWAT. Environmental Pollution. 2009; 157 (12): $3370-8$.

[28] Olivera F, Valenzuela M, Srinivasan R, Choi J, Cho H, Koka S, et al. ARCGIS-SWAT: A GEODATA MODEL AND GIS INTERFACE FOR SWAT 1. JAWRA Journal of the American Water Resources Association. 2006; 42 (2): 295309.

[29] Hrachowitz M, Soulsby C, Tetzlaff D, Malcolm I. Sensitivity of mean transit time estimates to model conditioning and data availability. Hydrological Processes. 2011; 25 (6): 980-90.

[30] Marino S, Hogue IB, Ray CJ, Kirschner DE. A methodology for performing global uncertainty and sensitivity analysis in systems biology. Journal of theoretical biology. 2008; 254 (1): $178-96$.

[31] Zhan C-S, Song X-M, Xia J, Tong C. An efficient integrated approach for global sensitivity analysis of hydrological model parameters. Environmental Modelling \& Software. 2013; 41: $39-52$.

[32] Setegn SG, Srinivasan R, Melesse AM, Dargahi B. SWAT model application and prediction uncertainty analysis in the Lake Tana Basin, Ethiopia. Hydrological Processes: An International Journal. 2010; 24 (3): 357-67. 
[33] Einheuser MD, Nejadhashemi AP, Sowa SP, Wang L, Hamaamin YA, Woznicki SA. Modeling the effects of conservation practices on stream health. Science of the total environment. 2012; 435: 380-91.

[34] Song X, Zhang J, Zhan C, Xuan Y, Ye M, Xu C. Global sensitivity analysis in hydrological modeling: Review of concepts, methods, theoretical framework, and applications. Journal of hydrology. 2015; 523: 739-57.
[35] Saha PP, Zeleke K, Hafeez M. Streamflow modeling in a fluctuant climate using SWAT: Yass River catchment in south eastern Australia. Environmental earth sciences. 2014; 71 (12): 5241-54.

[36] Roy K. On some aspects of validation of predictive quantitative structure-activity relationship models. Expert Opinion on Drug Discovery. 2007; 2 (12): 1567-77. 